\title{
Synthesis and Use of Imidazolium Bound Rose Bengal Derivatives for Singlet Oxygen Generation
}

\author{
Alioune Fall, ${ }^{\mathrm{b}}$ Massène Sène, ${ }^{\mathrm{b}}$ Ousmane Diouf, ${ }^{\mathrm{b}, *}$ Mohamed Gaye, ${ }^{\mathrm{b}}$ Generosa Gómez ${ }^{\mathrm{a}}$ and \\ Yagamare Fall, ${ }^{\mathrm{a}, *}$ \\ ${ }^{a}$ Departamento de Química Orgánica, Facultad de Ciencias. Universidad de Vigo, 36200 Vigo, Spain \\ ${ }^{b}$ Laboratoire de Chimie de Coordination Organique (LCCO), Departement de Chimie, Faculté des Sciences et Techni- \\ ques. Université Cheikh Anta Diop de Dakar, Sénégal
}

\begin{abstract}
We describe the preparation and use of two new imidazolium-bound Rose Bengal derivatives for singlet oxygen generation. Photolysis of oxygen-saturated solution of furan rings in the presence of the imidazolium-bound sensitizers provides the corresponding butenolides. The sensitizers could be recovered after the oxidation reaction.
\end{abstract}

Keywords: Ionic liquids, singlet oxygen, butenolides synthesis, rose Bengal, photooxygenation reactions.

\section{INTRODUCTION}

Singlet oxygen was originally proposed by Kautsky [1] as being an intermediate in the photosensitized oxidations. The process involves photochemical excitation of the sensitizer to its singlet excited state, intersystem crossing to triplet state, energy transfer to ground-state oxygen, and subsequent reaction of ${ }^{1} \mathrm{O}_{2}$ with an acceptor $\mathrm{A}$ to give oxygenated products $\mathrm{AO}_{2}$ (Scheme $\mathbf{1}$ ).

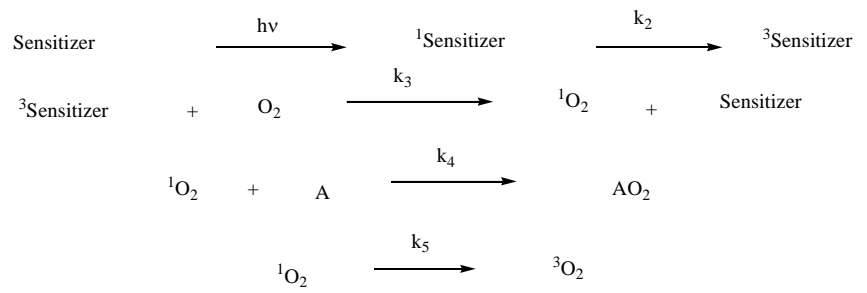

Scheme 1. Generation of singlet oxygen and its reaction with an acceptor A.

The chemical and photochemical generations of singlet molecular oxygen $\left({ }^{1} \mathrm{O}_{2}\right)$, its ready detection and its stereocontrolled chemical reactivity have made this research area very attractive and nowadays, photooxygenation reactions represent one of the most important hydrocarbon functionalization reactions for synthetic organic chemists [2]. These reactions are mild and preparatively useful because of their specificity and high yields.

\footnotetext{
*Address correspondence to these authors at the Departamento de Química Orgánica Facultad de Química Edificio Ciencias, Experimentales Universidad de Vigo, 36200 Vigo Pontevedra, Spain; Tel: (34) 9868123 20;

Fax: (34) 9868122 62; E-mail: yagamare@uvigo.es; and

Laboratoire de Chimie de Coordination Organique (LCCO), Departement de Chimie, Faculté des Sciences et Techniques. Université Cheikh Anta Diop de Dakar, Sénégal; Tel: 00221776515527; Fax: 00221 338246318;

E-mail: ousmanediouf37@yahoo.fr
}

\section{RESULTS AND DISCUSION}

As part of our ongoing programme on the synthesis of biologically active natural products we applied the oxidation of furan with singlet oxygen for the preparation of oxacyclic [3], carbocyclic [4], azacyclic [5] and thiacyclic [6] systems. For the photosensitized formation of singlet oxygen, the dye we used was Rose Bengal 1. However, one particular problem associated with this dye is its separation from the products. This has led to the synthesis of several immobilized Rose Bengal moieties using polymer or silica support [7]. Herein, we report the first synthesis of $\mathbf{2}$ and $\mathbf{3}$ (Fig. 1), two Rose Bengal derivatives linked to an imidazolium moiety.

Compounds $\mathbf{2}$ and $\mathbf{3}$ are imidazolium salts and may be considered as ionic liquids (ILs) depending on their melting point which by definition has to be below $100^{\circ} \mathrm{C}$ [8]. Ionic liquids (ILs) have received much attention in recent years from the scientific community, mainly as environmentally benign reaction media [9]. Their unique properties such as high thermal and chemical stability, negligible vapour pressure, non-flammability, high loading capacity and easy recyclability make them appealing for an organic chemist. The solubility of the ionic liquids can be tuned readily by modifying the structure of the cation or the anion, so that they can phase separate from organic as well as aqueous media, rendering purifications much easier. Rose Bengal derivative 2 was prepared via the synthetic route shown in Scheme 2.

Reaction of Rose Bengal 1 with propargyl bromide afforded alkyne 5 in $89 \%$ yield. Rose Bengal contains both carboxylate and phenoxide functional groups, either of which might be capable of reacting with propargyl bromide. However $\mathbf{5}$ was obtained as the major compound and could be separated from its minor isomer by column chromatography.

In order to link alkyne $\mathbf{5}$ to an ionic liquid support we needed to prepare compound $\mathbf{1 1}$ having an azide functional 

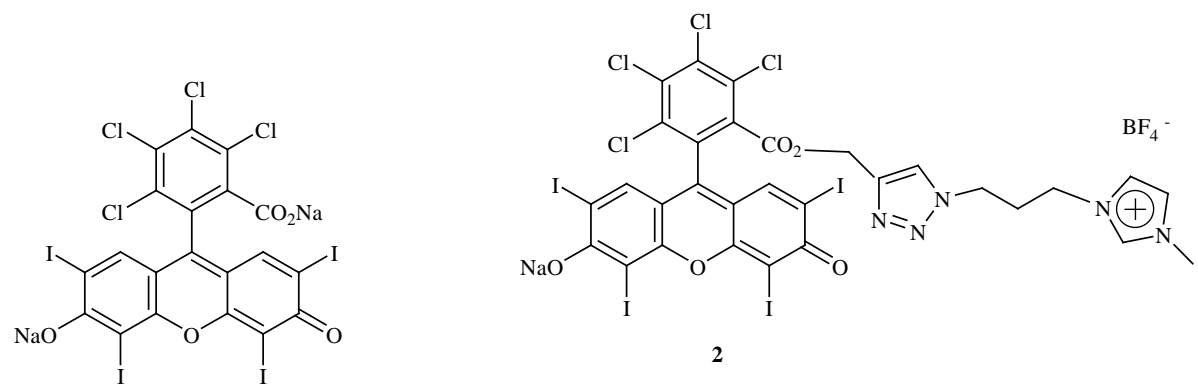

Rose Bengal 1

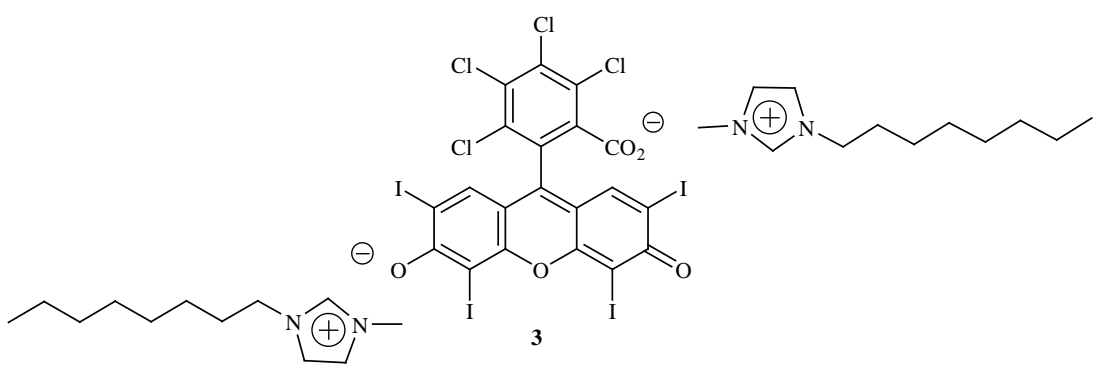

Fig. (1). Structures of Rose Bengal and two of its derivatives linked to an imidazolium moiety.<smiles>N#Cc1c(Cl)c(Cl)c(Cl)c(Cl)c1-c1c2cc(I)c(=O)c(I)c-2oc2c(I)c(O[N+](=O)[O-])c(I)cc12</smiles>
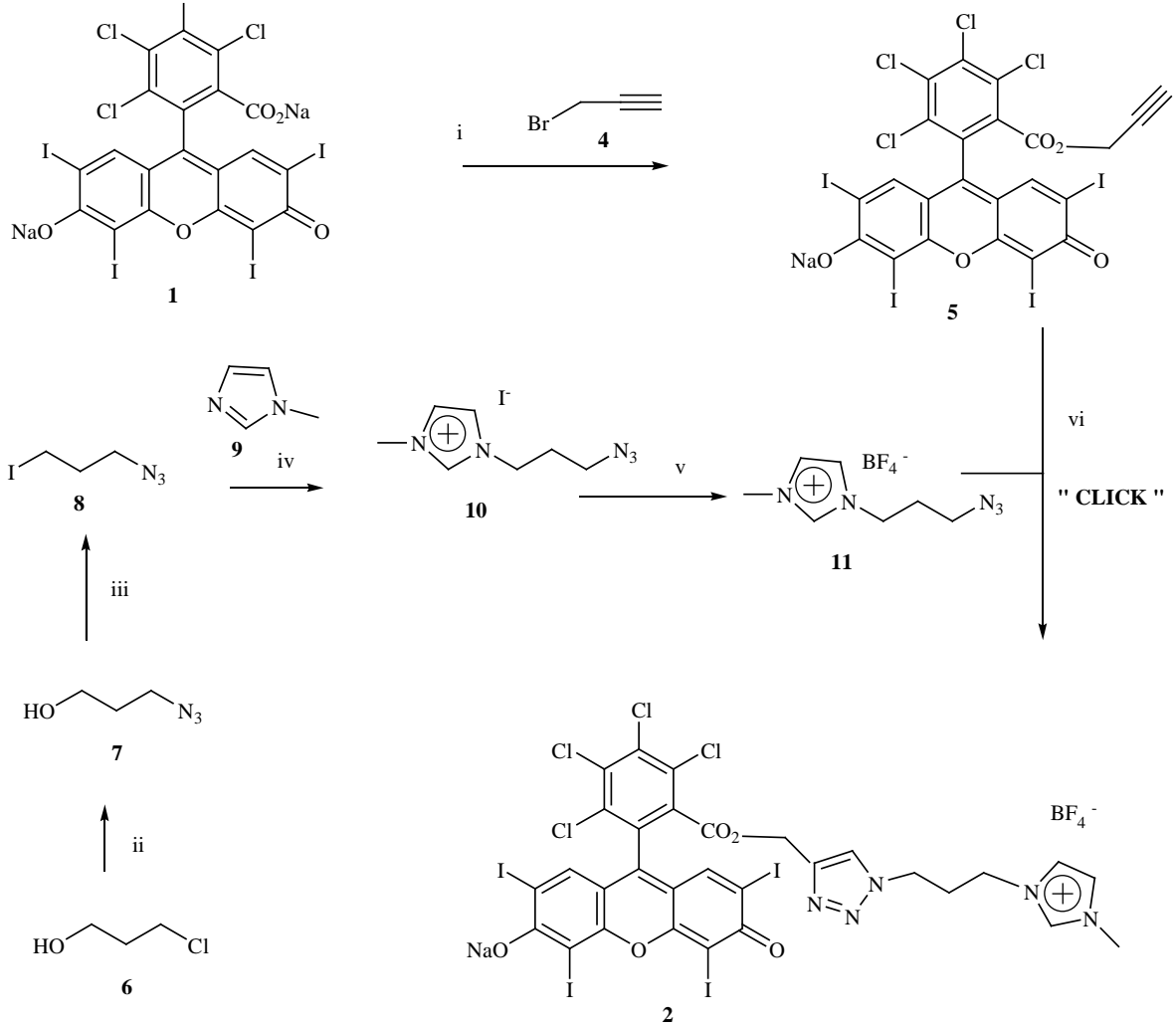

Scheme 2. Reagents and conditions: (i) 4, DMF, $80^{\circ} \mathrm{C}$ (89\%); (ii) $\mathrm{NaN}_{3}, \mathrm{H}_{2} \mathrm{O}$, reflux (98\%); (iii) $\mathrm{I}_{2}, \mathrm{PPh}_{3}$, Imidazole, THF (79\%); (iv) 9, rt (95\%); (v) $\mathrm{NaBF}_{4}, \mathrm{CH}_{3} \mathrm{CN}, 60^{\circ} \mathrm{C}(100 \%)$ (vi) $\mathrm{CuSO}_{4} \cdot 5 \mathrm{H}_{2} \mathrm{O}$, Na-ascorbate, $\mathrm{tBuOH} / \mathrm{H}_{2} \mathrm{O}(99 \%)$.

group in its side chain, so that we could use the click chemistry approach [10]. 11 was readily synthesized as follows: reaction of commercially available chloropropanol $\mathbf{6}$ with sodium azide gave an hydroxyl azide which was easily converted into iodide [11] 8. Reaction of iodide 8 with $\mathrm{N}$ methyl-imidazole $\mathbf{9}$ followed by anion exchange afforded ionic liquid 11 [12] in 95\% yield, setting the stage for the click chemistry reaction which occurred uneventfully to give almost quantitatively imidazolium-bound Rose Bengal 2, [12] hereafter designated as “IM-CLICK-RB” 2.

Diimidazolium salt 3 [12] herafter designated as Bis[OMIM]-RB was prepared from Rose Bengal in 60\% yield, via anion exchange according to Scheme $\mathbf{3}$. 
The melting points of the new Rose Bengal derivatives: IM-CLICK-RB 2 and Bis-[OMIM]-RB 3 were $252-254{ }^{\circ} \mathrm{C}$ and $68-70^{\circ} \mathrm{C}$ respectively, indicating that only 3 could be considered as ionic liquid.

We were interested in exploring the photocatalytic potential of $\mathbf{2}$ and $\mathbf{3}$ for the oxidation of furans, especially in comparison with Rose Bengal disodium salt (RB). For such purpose we selected the photocatalytic oxidation of furan $\mathbf{1 3}$ for the preparation of methoxybutenolide 15 (Scheme 4).

We have already reported the synthesis of methoxybutenolide $\mathbf{1 5}$ which was then used for the obtention of cyclic ethers. ${ }^{3 \mathrm{c}}$ Using RB as photosensitizer, furan $\mathbf{1 3}$ was oxidized in $7 \mathrm{~h}$ to the rather unstable hydroperoxide 14 which was then acetylated without further purification to afford $\mathbf{1 5}$ in $89 \%$ overall yield.

We carried out the same reaction on a 2 mmol scale, using RB 1, IM-CLICK-RB 2 and Bis-[OMIM]-RB 3 as photosensitizers in order to compare the overall yields and the reaction time for the oxidation of furan $\mathbf{1 3}$ to hydroperoxide 14. The results are summerized in Table $\mathbf{1}$.

As can be seen from Table $\mathbf{1}$, the photocatalytic performance of Bis-[OMIM]-RB $\mathbf{3}$ is superior to that of IM-

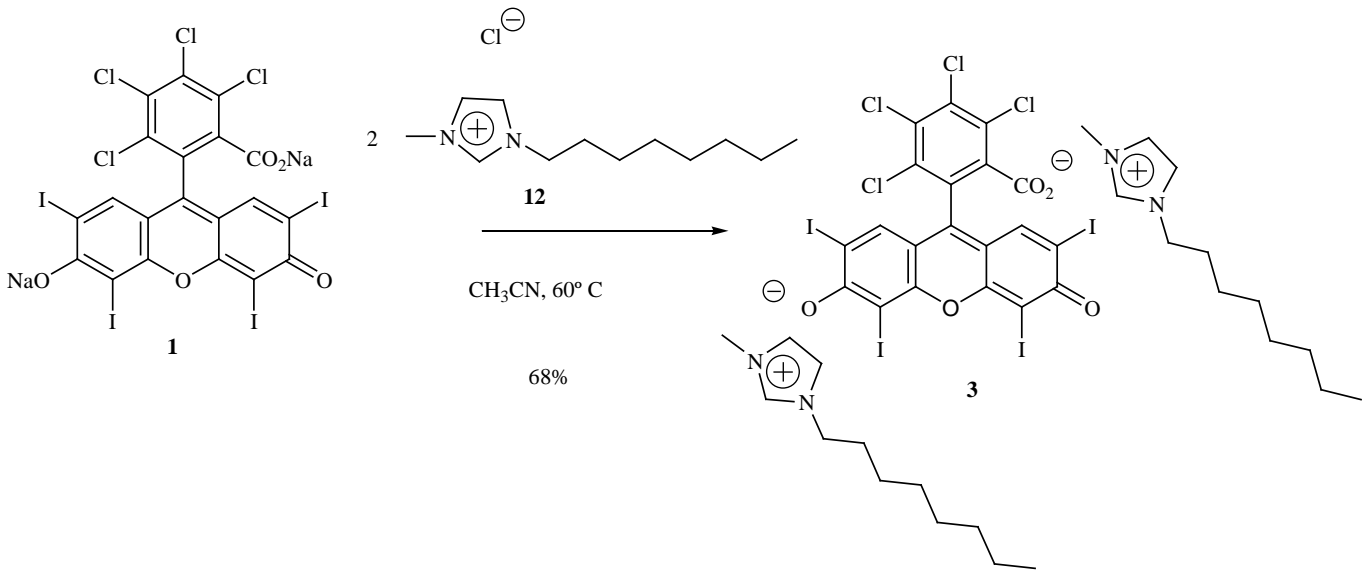

Scheme 3. Preparation of diimidazolium salt 3.

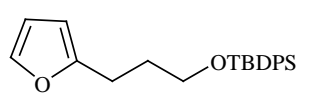

13
1) $\mathrm{O}_{2}$, hn, $\mathrm{MeOH}, \mathrm{RB},-78^{\circ} \mathrm{C}$

14

2) $\mathrm{Ac}_{2} \mathrm{O}$, py, DMAP

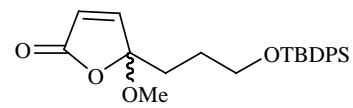

15

Scheme 4. Synthesis of methoxybutenolide $\mathbf{1 5}$ by photocatalytic oxidation of furan $\mathbf{1 3 .}$

Table 1. Comparison of the Photocatalytic Performance of Photosensitizers RB 1, IM-CLICK-RB 2 and Bis-[OMIM]-RB 3

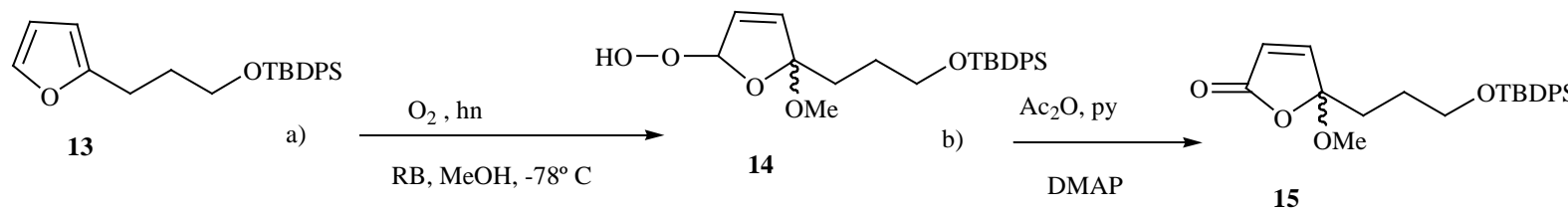

\begin{tabular}{llcl}
\hline Entry & Catalyst & Reaction time for step a (h) & Overall Yield (\%) \\
\hline 1 & RB & 2 & 31 \\
2 & IM-CLICK-RB (2) & 35 & 2
\end{tabular}


CLICK-RB 2 and RB, as indicated by the higher yield obtained for final butenolide $\mathbf{1 5 .}$

One noticeable difference between free RB $\mathbf{1}$ and its two derivatives IM-CLICK-RB 2 and Bis-[OMIM]-RB $\mathbf{3}$ is that in the case of RB the catalyst could not be recovered, whereas $\mathbf{2}$ and $\mathbf{3}$ were recovered as follows: after completion of the oxidation reaction (tlc), the methanol was rotatory evaporated and the residue taken up with ether $(15 \mathrm{ml})$. In this solvent , 2 and $\mathbf{3}$ were not soluble and were recovered by decantation, ready for another run.. The ether phase was concentrated and the resulting crude hydroperoxide $\mathbf{1 4}$ was further acetylated to afford methoxybutenolide $\mathbf{1 5 .}$

Recyclability studies were carried out for Bis-[OMIM]RB 3 as follows. We decided to use the same time (2 h) in the oxidation step for all the runs. After the first run the catalyst was recovered as above and reused after vacuum drying. The results are summarized in Table 2.

Table 2. Reuse of Bis-[OMIM]-RB 3 in Successive Reaction Cycles

\begin{tabular}{|c|c|c|}
\hline Cycle & Time[h] $^{\text {a }}$ & Yield [\%] $^{\mathbf{b}}$ \\
\hline \hline 1 & 2 & 87 \\
\hline 2 & 2 & 84 \\
\hline 3 & 2 & 85 \\
\hline 4 & 2 & 84 \\
\hline 5 & 2 & 83 \\
\hline 6 & 2 & 80 \\
\hline
\end{tabular}

After a total of six such cycles, yield was still high.

\section{CONCLUSIONS}

In conclusion, we have synthesized two new Rose Bengal derivatives, IM-CLICK-RB 2 and Bis-[OMIM]-RB 3 and used them as sensitizers for the generation of singlet oxygen. Bis-[OMIM]-RB $\mathbf{3}$ is an easily available ionic liquid which shows better photocatalytic performance than RB and IMCLICK-RB 2. Work is now in progress on the use of Bis[OMIM]-RB 3, in conjunction with ionic liquid as solvent for the singlet oxygen oxidation of furans.

\section{EXPERIMENTAL SECTION}

\section{General information}

Solvents were purified and dried by standard procedures before use. Melting points uncorrected.

${ }^{1} \mathrm{H}$ and ${ }^{13} \mathrm{C}$ NMR spectra were recorder in a Bruker ARX400 spectromer $\left(400 \mathrm{MHz}{ }^{1} \mathrm{H}, 100.61 \mathrm{MHz}{ }^{13} \mathrm{C}\right)$ using TMS as internal standard (chemical shifts in $\delta$ values, $J$ in $\mathrm{Hz}$ ). Mass spectrometry was carried out with a Hewlett Packard 5988A spectrometer. Flash chromatography (FC) was performed on silica gel (Merck 60, 230-400 mesh); analytical TLC was peformed on plates precoated with silica gel (Merck 60 F254, 0.25mmm).

\section{Synthesis of iodide Bis-[OMIM]-RB 3}

To a stirred solution of [OMIM][Cl] 12 (568 mg, 2.5 $\mathrm{mmol})$ in acetonitrile (15 mL) was added Rose Bengal 1 (1.25 g, $1.23 \mathrm{mmol})$. The mixture was stirred at $60{ }^{\circ} \mathrm{C}$ for 24 $\mathrm{h}$ then allowed to reach room temperature. The resulting precipitate was filtered, washed with acetonitrile (3 x $20 \mathrm{~mL}$ ) and the filtrate was concentrated under reduced pressure to afford a deep purple powder which was washed with AcOEt (3 x $20 \mathrm{~mL}$ ), dried under vacuum to afford 3 (1.14 g, 68\%). mp 68-70 ${ }^{\circ} \mathrm{C}$; IR $\left(\mathrm{CDCl}_{3}\right) 2923 ; 22852 ; 1614 ; 1545 ; 1460$; 1349; 1225; 1164; 950; 755; 623; 530; 448; $369 \mathrm{~cm}^{1}$; UV (MeOH, $\lambda(\mathbf{n m})$ ): 555; 518; 318; 211; ${ }^{\mathbf{1}} \mathbf{H}-\mathbf{N M R}\left(\mathbf{C D C l}_{3}\right)$

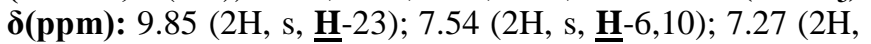
s, $\underline{\mathbf{H}}-25) ; 7.20$ (2H, s, $\underline{\mathbf{H}}-26) ; 4.08$ (4H, t, J = $7.51 \mathrm{~Hz}$, $\underline{\mathbf{H}}-28)$; 3.83 (6H, s, $\underline{\mathbf{H}}-36) ; 1.98$ (4H,m, $\underline{\mathbf{H}}-29) ; 1.77$ (4H, m, $\underline{\mathbf{H}}-30)$; $1.29-1.22$ (8H, m, $\underline{\mathbf{H}}-31,32,33, \overline{34}) ; 0.85(6 \mathrm{H}, \mathrm{t}, \mathrm{J}=7.09 \mathrm{~Hz}$, $\left.\underline{\mathbf{H}}-35) .{ }^{13} \mathbf{C}-N M R(\mathbf{C D C l})_{3}\right) \boldsymbol{\delta}(\mathbf{p p m}): 172.76(\underline{\mathbf{C}}-4,12) ; 167.12$ (C-21); 157.74 (ㄷ-2,14); 144.80; 144.00; 134.29; 131.02; 130.61; 128.36; 127.56 (ㅡ-20,15,16,17,18,19,8); 137.79 (ㄷH-23); 137.71 (ㄷH-6,10); 111.92 (ㄷ-7,9); 96.44 (드-3,13); 75.35 (드-5,11); $50.13\left(\underline{\mathbf{C H}}_{2}-28\right) ; 36.63\left(\underline{\mathbf{C H}}_{3}-36\right) ; 31.70$; 30.34; 29.08; 29.00; 26.33; $22.61\left(\mathrm{CH}_{2}-29,30,31,32,33\right.$, 34); $14.12\left(\mathbf{C H}_{3}-35\right)$. MS (ESI) (m/z, \%): ESI 391.28 (cation, 61). ESI 972.48 (anion, 100); 1166.65 (1cation + anion, 13).

\section{Synthesis of compound 5}

To a stirred solution of Rose Bengale (3.5 g, $3.5 \mathrm{mmol}$ ) in DMF (150 mL) was added propargyl bromide 4 (1,12 g, $9.4 \mathrm{mmol})$. The resulting mixture was stirred at $80^{\circ} \mathrm{C}$ for $3 \mathrm{~h}$. The DMF was distilled off under vacuo and the residue stirred in diethyl ether overnight. After filtration and thorough washing with diethyl ether, the residue was stirred with water for $6 \mathrm{~h}$ and filtered, to afford a deep purple powder which was dried under vacuum and purified by column chromatography on silica $\left(\mathrm{MeOH} / \mathrm{CH}_{2} \mathrm{Cl}_{2}, 5 / 95\right)$ to afford compound 5 (3.2 g, 89\%). $R_{f}=0.11\left(\mathrm{MeOH} / \mathrm{CH}_{2} \mathrm{Cl}_{2} 1: 9\right)$ ); IR $\left(\mathrm{CDCl}_{3}\right) 2348 ; 2301 ; 2100 ; 1740$ (C=O ester);1613; 1541; 1455; 1339; 1236; $1011 \mathrm{~cm}^{-1} ;{ }^{1} \mathrm{H}$ NMR (DMSO-d6, $400 \mathrm{MHz}) \delta 7.47$ (2H, s, CH-Ph); 4.64 (2H, d, J = $2.5 \mathrm{~Hz}$, CH2); $2.98\left(1 \mathrm{H}, \mathrm{t}, \mathrm{J}=2.4 \mathrm{~Hz}, \mathrm{CH}\right.$-alcyne); ${ }^{13} \mathrm{C} \mathrm{NMR}$ (DMSO-d6, $400 \mathrm{MHz}) \delta 171.62$ (C-3,5); 162.29 (C=O); 156.98 (C-4a,4b); 138.93; 135.21; 134.35; 132.64; 131.87; 130.12; 128.79 (C-1', 2', 3', 4', 5',6', 9);135.96 (C-1,8); 110.46 (C-8a, 8b); 97.23 (C-4,5); 77.30 (CH-alcyne); 76.24 (C-2,7); 53.43 (CH2). ; EI-HRMS calcd for $\mathrm{C}_{23} \mathrm{H}_{5} \mathrm{Cl}_{4} \mathrm{I}_{4} \mathrm{NaO}_{5}$ $(\mathrm{m} / \mathrm{z})\left[\mathrm{M}^{+}\right]$1033.7025, found 1033.5074.

\section{Synthesis of azide 7}

To a solution of $\mathrm{NaN}_{3}(5.82 \mathrm{~g}, 89.6 \mathrm{mmol})$ in $\mathrm{H}_{2} \mathrm{O}(70$ $\mathrm{mL}$ ) was added portionwise 6 (3.00 $\mathrm{mL}, 44.8 \mathrm{mmol})$. The mixture was refluxed for $16 \mathrm{~h}$ then allowed to reach room temperature and extracted with $\mathrm{CH}_{2} \mathrm{Cl}_{2}(80 \mathrm{~mL} \times 3)$. The combined organic layers were dried over $\mathrm{Na}_{2} \mathrm{SO}_{4}$, filtered and the solvent rotatory evaporated to afford azide 7 as a colourless liquid (2.37 g, 98\%). $R_{f}=0.46$ (EtOAc/hexane 3:7); ${ }^{1} \mathbf{H}-\mathbf{N M R}\left(\mathbf{C D C l}_{3}, \boldsymbol{\delta}\right): 3.63$ (2H, q, J = 5.07, $\left.\underline{\mathbf{H}}-1\right)$; 3.35

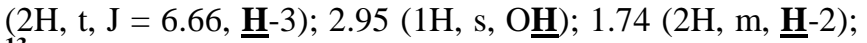
${ }^{13} \mathbf{C}-\mathrm{NMR}\left(\mathbf{C D C I} \mathbf{I}_{3}, \boldsymbol{\delta}\right): 59.30\left(\underline{\mathrm{CH}}_{2}-1\right) ; 48.14\left(\underline{\mathrm{CH}}_{2}-3\right) ; \overline{1} .22$ $\left(\underline{C H}_{2}-2\right)$; $\mathbf{M S}\left(\mathbf{E I}^{+}\right)(\mathbf{m} / \mathbf{z}, \mathbf{\%}): 86.06\left(\left[\mathrm{C}_{3} \mathrm{H}_{6} \mathrm{ON}_{2}\right]^{+}, 100\right)$. 


\section{Synthesis of iodide 8}

To a vigourously stirred solution of azide 7 ( 8.14 g, 80.6 $\mathrm{mmol})$ in THF (150 $\mathrm{mL}$ ) and under argon atmosphere were added $\mathrm{PPh}_{3}$ (25.36 g, $\left.96.36 \mathrm{mmol}\right)$ and imidazole (16.46 g, $241.8 \mathrm{mmol}$ ). The mixture was stirred until total dissolution of the reagents, then cooled to $-20{ }^{\circ} \mathrm{C}$, before adding portionwise $\mathrm{I}_{2}$ (26.59 g, $104.78 \mathrm{mmol}$ ) dissolved in THF (50 $\mathrm{mL}$ ). The reaction mixture was stirred at $-20{ }^{\circ} \mathrm{C}$ for $10 \mathrm{mn}$, then allowed to reach room temperature for $30 \mathrm{mn}$. The reaction mixture was spurred into ice-water and an saturated aqueous solution of $\mathrm{NaHCO}_{3}(100 \mathrm{~mL})$ was added. A precipitate was formed, which was filtered and the filtrate extracted with ether ( $3 \times 120 \mathrm{~mL})$. The combined organic layers were dried over $\mathrm{Na}_{2} \mathrm{SO}_{4}$, filtered and the solvent rotatory evaporated to afford a residue which was purified by column chromatography on silica (hexane/EtOAc, 7/3) to afford compound 8 (13.4 g, 99\%) as a yellow oil. $R_{f}=0.78$ (hexane/EtOAc, 7/3); ${ }^{1} \mathbf{H}-\mathbf{N M R}\left(\mathbf{C D C l}_{3}, \boldsymbol{\delta}\right): 3.42(2 \mathrm{H}, \mathrm{t}, \mathrm{J}=$ $6.34 \mathrm{~Hz}, \underline{\mathbf{H}}-3) ; 3.24(2 \mathrm{H}, \mathrm{t}, \mathrm{J}=6.64 \mathrm{~Hz}, \underline{\mathbf{H}}-1) ; 2.03(2 \mathrm{H}, \mathrm{m}, \mathrm{H}-$ 2); ${ }^{13} \mathbf{C}-\mathbf{N M R}\left(\mathbf{C D C l}_{3}, \boldsymbol{\delta}\right): 51.48\left(\underline{\mathbf{C H}}_{2}-3\right) ; 32.34\left(\underline{\mathrm{CH}}_{2}-2\right)$; $2.49\left(\underline{\mathrm{CH}}_{2}-1\right)$.

\section{Synthesis of ionic liquid 10}

To iodide 8 (3.31 g, $16.82 \mathrm{mmol}$ ) was added methylimidazole $9(1.47 \mathrm{~mL}, 18.5 \mathrm{mmol})$ and the mixture stirred at room temperature for $48 \mathrm{~h}$. The resulting yellow and viscous oil was washed with EtOAc AcOEt ( $5 \times 25 \mathrm{~mL}$ ) to yield ionic liquid 10 (4.37 g; $95 \%)$; ${ }^{1} \mathbf{H}-\mathbf{N M R}\left(\mathbf{D}_{2} \mathbf{O}, \boldsymbol{\delta}\right)$ : 8.69 (1H, s, 브-2) ; 7.42 (1H, s, $\underline{\mathbf{H}}-4) ; 7.35$ (1H, s, $\underline{\mathbf{H}}-5)$; 4.21(2H, t, J = $6.9 \mathrm{~Hz}, \underline{\mathbf{H}}-6) ; 3.80(3 \mathrm{H}, \mathrm{s}, \underline{\mathbf{H}}-9) ; 3.33(2 \mathrm{H}, \mathrm{t}, \mathrm{J}$ $=6.9, \underline{\mathbf{H}}-8) ; 2.06(2 \mathrm{H}, \overline{\mathrm{q}}, \mathrm{J}=6.7 \mathrm{~Hz}, \underline{\mathbf{H}}-7) ;{ }^{13} \mathbf{C}-\mathbf{N M R}\left(\mathbf{D}_{\mathbf{2}} \mathbf{O}\right.$,

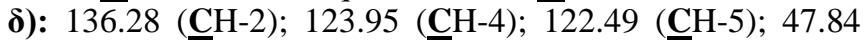
$\left(\underline{\mathbf{C H}}_{2}-6\right) ; 47.04\left(\mathrm{CH}_{2}-8\right) ; 36.37\left(\underline{\mathbf{C H}}_{3}-9\right) ; 28.78\left(\underline{\mathbf{C H}}_{2}-7\right)$; IR$\left(\mathbf{C D C l}_{3}, \mathbf{v}\left(\mathrm{cm}^{-1}\right)\right): 3463 ; 3081 ; 2871 ; 2102 ; 1569 ; 1455$; 1455; 1265; 1166; 1062; 829; 752; 619; MS (ESI $\left.{ }^{+}\right)$(m/z, \%): 166.11 (cation, 100).

\section{Synthesis of ionic liquid 11}

To a solution of $\mathbf{1 0}$ (5.23 g, $17.86 \mathrm{mmol})$ in acetonitrile $(40 \mathrm{~mL})$ was added $\mathrm{NaBF}_{4}(2.20 \mathrm{~g}, 19.64 \mathrm{mmol})$. The mixture was stirred at $60^{\circ} \mathrm{C}$ for $48 \mathrm{~h}$ and the resulting precipitate was filtered off, washed with acetonitrile and the filtrate concentrated under vacuum to afford a yellow viscous oil 11 (4.51 g, 100\%); ${ }^{\mathbf{1}} \mathbf{H}-\mathbf{N M R}\left(\mathbf{D}_{\mathbf{2}} \mathbf{O}, \boldsymbol{\delta}\right)$ : $8.71(1 \mathrm{H}, \mathrm{s}, \underline{\mathbf{H}}-2) ; 7.45(1 \mathrm{H}$, s, $\underline{\mathbf{H}}-4) ; 7.39$ (1H, s, $\underline{\mathbf{H}}-5) ; 4.25$ (2H, t, J = $6.9 \mathrm{~Hz}, \underline{\mathbf{H}}-6)$; 3.83 $(3 \mathrm{H}, \mathrm{s}, \underline{\mathbf{H}}-9) ; 3.37(2 \mathrm{H}, \mathrm{t}, \mathrm{J}=6.4 \mathrm{~Hz}, \underline{\mathbf{H}}-8) ; 2.10(2 \mathrm{H}, \mathrm{q}, \mathrm{J}=$ $6.6 \mathrm{~Hz}, \underline{\mathbf{H}}-7) ;{ }^{13} \mathbf{C}-\mathbf{N M R}\left(\mathbf{D}_{2} \mathbf{O}, \boldsymbol{\delta}\right): 136.18$ (CH-2); 123.82 (ㅡH-4); 122.34 (ㅡH-5); $47.70 \quad\left(\underline{\mathbf{C H}_{2}}-7\right) ; 46.88\left(\underline{\mathbf{C H}}_{2}-8\right)$; $36.02\left(\mathrm{CH}_{3}-9\right)$; $28.58\left(\mathrm{CH}_{2}-7\right)$; IR-( $\left.\mathbf{C D C l}_{3}, \mathbf{v}\left(\mathrm{cm}^{-1}\right)\right)$ : 3463; 3081; 2102; 1569; 1455; 1265; 1166; 1058; 831; 769; 619; MS (ESI ${ }^{+}$(m/z, \%): 166.12 (cation, 100); 167.11 (12); 225.15(2.35).

\section{Synthesis of IM-CLICK-RB 2}

To a solution of ionic liquid 11 (528.7 mg, $2.09 \mathrm{mmol}$ ) in $30 \mathrm{~mL}$ of $\mathrm{tBuOH} / \mathrm{H}_{2} \mathrm{O}(2 / 1)$ was added compound 5 (2.33 g, $5.95 \mathrm{mmol})$ a catalytic amount of $\mathrm{CuSO}_{4} \cdot 5 \mathrm{H}_{2} \mathrm{O}(5 \%)$, sodium ascorbate $(0.42 \mathrm{~mL}, 0.42 \mathrm{mmol}$ of an $1 \mathrm{M}$ solution). The reaction mixture was stirred at room temperature overnight.
At the end of the reaction, the solvent was evaporated and the resulting solid was washed with $\mathrm{Et}_{2} \mathrm{O}(3 \mathrm{x} 15 \mathrm{~mL})$, EtOAc ( 3 x $15 \mathrm{~mL}), \mathrm{MeOH}(3 \times 15 \mathrm{~mL})$ then dried under vacuum to afford 2 (2.3 g, 86\%) as a rose solid. $\mathrm{mp} 235-237$ ${ }^{\circ} \mathrm{C}$; ${ }^{1} \mathbf{H}-N M R$ (DMSO-d $\mathbf{d}_{\mathbf{6}}$ ) $\boldsymbol{\delta}$ (ppm): 9.50 (1H, s, $\left.\underline{\mathbf{H}}-32\right) ; 7.90$ $(1 \mathrm{H}, \mathrm{t}, \mathrm{J}=1.75 \mathrm{~Hz}, \mathrm{C} \underline{\mathbf{H}}-27) ; 7.80 ; 7.79$ (2H, s, $\underline{\mathbf{H}}-34,35) ; 7.63$ (2H, s, $\underline{\mathbf{H}}-6,10) ; 4.68$ (2H, d, J = $2.46 \mathrm{~Hz}, \underline{\mathbf{H}}-22) ; 4.56$ (2H, t, $\mathrm{J}=7.15 \mathrm{~Hz}, \underline{\mathbf{H}}-30) ; 4.12$ (3H, s, $\underline{\mathbf{H}}-35) ; 3.57(2 \mathrm{H}, \mathrm{t}, \mathrm{J}=6.57$ $\mathrm{Hz}, \underline{\mathbf{H}}-28) ; 2.29$ (2H, m, $\underline{\mathbf{H}}-29)$; ${ }^{13}$ C-NMR (DMSO-d (D) $^{2}$ $\delta(\mathbf{p p m}): 174.19(\underline{\mathbf{C}}-4,12) ; 164.21(\underline{\mathbf{C}}=0) ; 159.66(\underline{\mathbf{C}}-2,14)$; 141.29; 137.45; 136.61; 135.47; 134.32; 132.86; 131.47 (C$20,15,16,17,18,19,8) ; 138.39(\underline{\mathbf{C} H}-6,10) ; 125.81$ (드-

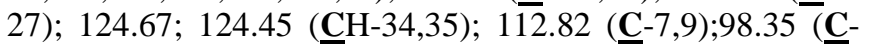
3,13); $75.99(\underline{\mathbf{C}}-5,11) ; 54.89\left(\underline{\mathbf{C H}}_{2}-22\right) ; 49.73 ; 48.88$ (C) 28,30); 37.93 (C-35); $31.52\left(\mathrm{CH}_{2}-29\right)$; IR-(CDCl $\left.\mathbf{3}, \mathbf{v}\left(\mathrm{cm}^{-1}\right)\right)$ : 2360; 2098; $1743(\mathrm{C}=\mathrm{O})$; 1614; 1546; 1459; 1344; 1247; 1168; 952; 754; 663; 522; 435; UV (MeOH, $\lambda(\mathbf{n m})$ ): 564; 285; 273; 266; 207; $\mathbf{M S ~}\left(\mathbf{E I}^{+}\right)[\mathbf{m} / \mathbf{z},(\mathbf{\%})]: \quad X=\mathrm{I}:$ 1175.62 $\left(\left[\mathrm{C}_{33} \mathrm{H}_{19} \mathrm{Cl}_{4} \mathrm{I}_{4} \mathrm{~N}_{3} \mathrm{NaO}_{3}\right]^{+}, 100\right) ; \mathrm{X}=\mathrm{BF}_{4}: 1177.6182$ $\left([\mathrm{M}-\mathrm{Na}]^{+} 100\right) ; 1175.62\left(\left[\mathrm{C}_{11} \mathrm{H}_{10} \mathrm{Cl}_{4} \mathrm{I}_{4} \mathrm{~N}_{23} \mathrm{NaO}_{4}\right]^{+}, 86\right)$.

\section{ACKNOWLEDGEMENTS}

This work was financially supported by the Spanish Ministry of Foreign Affairs and Cooperation (PCI A/030052/10) and the Xunta de Galicia (INCITE08PXIB314253PR, INCITE08ENA314019ES and INCITE08PXIB314255PR). The work of the NMR and MS divisions of the research support services of the University of Vigo (CACTI) is also gratefully acknowledged. A. Fall and M. Sène thank Asiyla Gum company SARL for research fellowships.

\section{CONFLICT OF INTEREST}

None declared.

\section{SUPPORTING INFORMATION}

Supporting Information is available on the publisher's web site along with the published article.

\section{REFERENCES}

[1] (a) Kautsky, H.; de Bruijn, H. The explanation of the inhibition of photoluminescence of fluorescent systems by oxygen: the formation of active, diffusing oxygen molecules by sensitization. Naturwissenschaften, 1931, 19, 1043. (b) Kautsky, H.; de Bruijn, H.; Neuwirth, R.; Baumeister, W. Energy transfers at surfaces. VII. Photosensitized oxidation as the action of an active, metastable state of the oxygen molecule. Chem. Ber., 1933, 66, 1588-1600. (c) Kautsky, H. Quenching of luminescence by oxygen. Trans. Faraday Soc., 1939, 35, 216-219.

[2] (a) Prein, M.; Adam, W. The Schenck ene reaction: diastereoselective oxyfunctionalization with singlet oxygen in synthetic applications. Angew. Chem., Int. Ed. Engl., 1996, 35, 477494. (b) Clennan, E. L. New Mechanistic and Synthetic Aspects of Singlet Oxygen Chemistry. Tetrahedron, 2000, 56, 9151-9179 (c) Paquette, L. A.; Tac, J.; Arrington, M. P.; Sadoun, A. H. Enantioselective double michael addition/cyclization with an oxygen-centered nucleophile as the first step in a concise synthesis of natural (+)-asteriscanolide. J. Am. Chem. Soc., 2000, 122, 27422748. (d) Adam, W.; Saha-Möller, C. R.; Schmid, K. S. Synthesis of 4,6-Dideoxyfuranoses through the regioselective and diastereoselective oxyfunctionalization of a dimethylphenylsilylsubstituted chiral homoallylic alcohol. J. Org. Chem., 2001, 66, 7365-7371. (e) Vassilikogiannakis, G.; Stratakis, M. Biomimetic total synthesis of litseaverticillols A, C, D, F, and G: Singletoxygen-initiated cascades. Angew. Chem., Int. Ed. Engl., 2003, 42, 
5465-5468 (f) Clennan, E. L.; Pace, A. Advances in singlet oxygen chemistry. Tetrahedron, 2005, 61, 6665-6691. (g) Vassilikogiannakis, G.; Margaros, I.; Montagnon, T.; Stratakis, M. Illustrating the power of singlet oxygen chemistry in a synthetic context: Biomimetic syntheses of litseaverticillols A-G, I and J and the structural reaccignment of litseaverticillol E. Chem. Eur. J., 2005, 11, 5899-5907.(h) Margaros, I.; Montagnon, T.; Tofi, M.; Pavlakos, E.; Vassilikogiannakis, G. The power of singlet oxygen chemistry in biomimetic syntheses. Tetrahedron, 2006, 62, 53085317. (i) Alberti, M. N.; Orfanopoulos, M. Stereoelectronic and solvent effects on the allylic oxyfunctionalization of alkenes with singlet oxygen. Tetrahedron, 2006, 62, 10660-10675.

[3] (a) Fall, Y.; Vidal, B.; Alonso, D.; Gómez, G. Synthesis of sevenmembered oxacycles. Part 2: The furan approach. Tetrahedron Lett., 2003, 44, 4467-4469. (b) Pérez, M.; Canoa, P.; Gómez, G.; Terán, C.; Fall, Y. The furan approach to oxacycles: synthesis of medium-size 2,3-disubstituted oxacycles. Tetrahedron Lett., 2004, 45, 5207-5209. (c) Alonso, D.; Pérez, M.; Gómez, G.; Covelo, B.; Fall, Y. The furan approach to oxacycles, Part 3: Stereoselective synthesis of 2,3-disubstituted tetrahydropyrans. Tetrahedron, 2005, 61, 2021-2026. (d) Teijeira, M.; Suárez, P. L.; Gómez, G.; Terán, C., Fall, Y. The furan approach to oxacycles, Part 5: Synthesis of a chiral butenolide, building block towards biologically interesting natural products. Tetrahedron Lett., 2005, 46, 5889-5892. (e) García, I; Gómez, G.; Teijeira, M.; Terán, C.; Fall, Y. The furan approach to oxacycles, Part 4: A synthesis of (+)-decarestrictine L. Tetrahedron Lett., 2006, 47, 1333-1335. (f) Canoa, P.; Pérez, M.; Covelo, B.; Gómez, G.; Fall, Y. The furan approach to oxacycles, Part 6: From THF to fused polyoxepanes. Tetrahedron Lett., 2007, 48, 3441-3443. (g) Canoa, P.; Vega, N.; Pérez, N.; Gómez, G.; Fall, Y. Stereoselective synthesis of polytetrahydropyrans. Tetrahedron Lett., 2008, 49, 1149-1151. (h) García, I.; Pérez, M.; Besada, P.; Gómez, G.; Fall, Y. Synthetic studies toward zoapatanol. Tetrahedron Lett., 2008, 49, 1344-1347. (i) Estévez, L.; Besada, P.; Fall, Y., Teijeira, M.; Terán, C. Stereoselective synthesis of novel isonucleoside analogs of purine with a tetrahydropyran ring. Synthesis, 2010, 3, 425-430. (j) Fall, A.; Sène, M.; Tojo, E.; Gómez, G.; Fall, Y. Use of ionic liquid as solvent in the oxidation of furans with singlet oxygen. Synthesis, 2010, 20, 3415-3417. (k) Álvarez, C.; Pérez, M.; Zúñiga, A.; Gómez, G.; Fall, Y. Synthesis of enantiomerically pure 2,5-disubstituted 3-oxygenated tetrahydrofurans. Synthesis, 2010, 22, 3883-3890. (l) Canoa, P.; Gándara, Z.; Pérez, M.; Gago, R.; Gómez, G.; Fall, Y. The furan approach to oxacycles: new entry to the synthesis of isodideoxynucleosides. Synthesis, 2010, 3, 431-436. (m) González, M.; Gándara, Z.; Covelo, B.; Gómez, G.; Fall, Y. Total synthesis of (-)-muricatacin. Tetrahedron Lett., 2011, 52, 5983-5986.

[4] Gómez, G.; Rivera, H.; García, I.; Estevez, L.; Fall, Y. The furan approach to carbocyclic systems. Synthesis of cyclohexane derivatives from butenolides through an intramolecular Michael addition. Tetrahedron Lett., 2005, 46, 5819-5822.

[5] García, I.; Pérez, M.; Gándara, Z.; Gómez, G.; Fall, Y. The furan approach to azacyclic compounds. Tetrahedron Lett., 2008, 49, 3609-3612.

[6] (a) Boullosa, S.; Gándara, Z.; Pérez, M.; Gómez, G.; Fall, Y. The furan approach to thiacyclic compounds. Stereoselective synthesis of 2,3-disubstituted tetrahydrothiopyrans. Tetrahedron Lett., 2008, 49, 4040-4042. (b) Besada, P.; Pérez, M.; Gómez, G.; Fall, Y.
Stereoselective synthesis of 2,3,4-trisubstituted tetrahydrothiophenes. Tetrahedron Lett., 2009, 50, 6941-6943.

[7] (a) Schaap, A. P.; Thayer, A. L.; Blossey, E. C.; Neckers, D. C. Polymer-based sensitizers for photooxidations. II. J. Am. Chem. Soc., 1975, 97, 3741-3745.(b) Tamagaki, S.; Liesner, C. E.; Neckers, D. C. Polymer-based sensitizers for photochemical reactions. Silica gel as a support. J. Org. Chem., 1980, 45, 1573-1576. (c) Facchin, G.; Minto, F.; Gleria, M.; Bertani, R.; Bortolus, P. Phosphazene-bound Rose Bengal: a novel photosensitizer for singlet oxygen generation. J. Inorg. Organomet. Polym., 1991, 1, 389395. (d) Alcantara, R.; Canoira, L.; Joao, P. G.; Rodríguez, J. G.; Vazquez, I. Photoxidation of ethylbenzene with air catalyzed by a polymer supported Rose Bengal photosensitizer. J. Photochem. Photobiol. A: Chem., 2000, 133, 27-32. (e) Burguete, M. I.; Gavara, R.; Galindo, F.; Luis S. V. Synthetic application of photoactive porous monolithic polymers. Tetrahedron Lett., 2010, 51, 3360-3363.

[8] (a) Wasserscheid, P.; Bösmann, A.; Bolm, C. Synthesis and properties of ionic liquids derived from the "chiral pool". Chem. Commun., 2002, 3, 200-201.

[9] For recent reviews on ionic liquids, see: (a) Welton, T. RoomTemperature Ionic Liquids, solvents for Synthesis and Catalysis. Chem. Rev., 1999, 99, 2071-2083. (b) Wasserscheid, P.; Keim, W. Ionic liquids. New "solutions" for transition metal catalysis. Angew. Chem., Int. Ed., 2000, 39, 3772-3789. (c) Sheldon, R. Catalytic reactions in ionic liquids. Chem. Commun., 2001, (23), 2399-2407. (d) Wilkes, J. S. A short history of ionic liquids. From molten salts to neoteric solvents. Green Chem., 2002, 4, 73-80. (e) Scammells, P. J.; Scott, J. L.; Singer, R. D. Ionic liquids: the neglected issues. Aust. J. Chem., 2005, 58, 155-169. (f) Bica, K.; Gaertner, P. Applications of chiral ionic liquids. Eur. J. Org. Chem., 2008, (19), 3235-3250.

[10] (a) Huisgen, R.; Knorr, R.; Moebius, L.; Szeimies, G. 1,3-Dipolar cycloaddition. XXIII. Addition of organic azides to C-C triple bonds. Chem. Ber., 1965, 98, 4014-4021. (b) Huisgen, R. Kinetic and reaction mechanisms: selected examples from the experience of forty years. Pure Appl. Chem., 1989, 61, 613-628. (c) Kolb, H. C.; Finn, M. G.; Sharpless, K. B. Click chemistry: diverse chemical function from a few good reactions. Angew. Chem., Int. Ed. Engl., 2001, 40, 2004-2021. (d) Tornoe, C. W.; Christensen, C.; Meldal, M. Peptidotriazoles on solid phase: [1,2,3]-triazoles by regiospecific copper(I)-catalyzed 1,3-dipolar cycloadditions of terminal alkynes to azides. J. Org. Chem., 2002, 67, 3057-3064. (e) Rostovtsev, V. V.; Green, L. G.; Fokin, V. V.; Sharpless, K. B. A stepwise Huisgen cycloaddition process: copper(I)-catalyzed regioselective "ligation" of azides and terminal alkynes. Angew. Chem., Int. Ed. Engl., 2002, 41, 2596-2599. (f) Bock, V. D.; Hiemstra, H.; van Maarseveen, J-H. Cu(I)-catalyzed alkyne-azide click cycloadditions from a mechanistic and synthetic perspective. Eur. J. Org. Chem., 2006, 1, 51-68. (g) Meldal, M.; Tornoe, C. W. Cu-Catalyzed Azide-Alkyne Cycloaddition. Chem. Rev., 2008, 108, 2952-3015.

[11] Pérez-Sestelo, J.; Mascareñas, J. L.; Castedo, L., Mouriño, A. Ultrasonically induced conjugate addition of iodides to electrondeficient olefins and its application to the synthesis of side-chain analogs of the hormone $1 \alpha, 25$-dihydroxyvitamin $\mathrm{D}_{3}$. J. Org. Chem., 1993, 58, 118-123.

[12] The spectral data of $\mathbf{2}$ and $\mathbf{3}$ can be found in the supplementary material. 